\title{
Association of Organizational Culture and Climate With Variation in the Clinical Outcomes of Collaborative Care for Maternal Depression in Community Health Centers
}

Nathaniel J Williams

Boise State University

Joan Russo

University of Washington Seattle Campus: University of Washington

Melinda Vredevoogd

University of Washington Seattle Campus: University of Washington

\section{Tess Grover}

University of Washington Seattle Campus: University of Washington

Phillip Green

The University of Tennessee System

\section{Enola Proctor}

Washington University In St Louis: Washington University in St Louis

\section{Amritha Bhat}

University of Washington Seattle Campus: University of Washington

\section{Jurgen Unutzer}

University of Washington Seattle Campus: University of Washington

lan M Bennett ( $\nabla$ ibennett@uw.edu )

University of Washington Seattle Campus: University of Washington 7139-9456

https://orcid.org/0000-0002-

\section{Research}

Keywords: depression, maternal, collaborative care, implementation, sustainment, organizational culture, organizational climate

Posted Date: March 11th, 2021

DOl: https://doi.org/10.21203/rs.3.rs-278564/v1

License: (c) (1) This work is licensed under a Creative Commons Attribution 4.0 International License. Read Full License 
Page $2 / 26$ 


\section{Abstract}

\section{Background}

Organizational culture and climate may help explain variation in the effectiveness of evidence-based practices implemented in primary care settings; however, this hypothesis has not been well tested. This study tested the relationship between organizational culture and climate and variation in clinical outcomes of the evidence-based collaborative care model (CoCM) for maternal depression implemented in primary care health centers serving low income populations.

\section{Methods}

Organizational cultures and climates of ten community health centers providing collaborative care for depression among women in pregnancy and parenting were assessed using the Organizational Social Context (OSC) measure. Three-level hierarchical linear models tested whether variation in culture and climate predicted variation in improvement in depression symptoms from baseline to 6.5 months postbaseline for $\mathrm{N}=468$ women who initiated care in the year before and after the OSC assessment. Depression symptomology was measured using the Patient Health Questionnaire (PHQ-9).

Results

After controlling for patient characteristics, case mix, center size, and implementation support, patients served by health centers with more proficient cultures improved significantly more from baseline to 6.5 months post-baseline than patients served by centers with less proficient cultures (mean improvement $=$ 5.08 vs. 0.14 , respectively, $P<.05$ ), resulting in a large adjusted effect size of $d_{a d j}=0.78$. A similar effect was observed for patients served by centers with more functional climates (mean improvement $=5.25 \mathrm{vs}$. $1.12, P<.05, d_{a d j}=0.65$ ). Growth models indicated that, on average, patients served by centers with more proficient cultures recovered after four months of care and remained stabilized below the clinical cutoff at 6.5 months post-baseline, whereas patients served by centers with less proficient cultures improved after four months but then deteriorated to above the clinical cutoff by 6.5 months post-baseline $(P<0.05)$. A similar pattern was observed for functional climate.

\section{Conclusions}

Variation in clinical outcomes for women from vulnerable populations receiving collaborative care for maternal depression was associated with the organizational cultures and climates of primary care health centers. Implementation strategies that target proficient culture and functional climate may improve the implementation and effectiveness of integrated behavioral health care for depression by reducing this variation.

\section{Contributions To The Literature}


- Many implementation frameworks and theories espouse the importance of organizational culture and climate for influencing the implementation and effectiveness of evidence-based practices in primary care settings; however, empirical studies that test this hypothesis using clinical outcomes as an endpoint are rare.

- This study showed that the extent to which patients benefitted from the evidence-based collaborative care model for depression was related to the prevailing culture and climate of community health centers where they received treatment independent of other factors known to be associated with these outcomes.

- Implementation strategies that target organizational culture (i.e., priorities and expectations for staff) and climate (i.e., quality of working environment) may improve the clinical outcomes of integrated collaborative care models for depression and reduce observed variation in outcomes across these clinics.

\section{Background}

Globally, depression is the greatest cause of disabled years lived and accounts for more than 200 billion USD in annual costs in the US from treatment and lost productivity. ${ }^{1,2}$ Maternal depression, including mood disorders occurring in pregnancy and parenting, affects approximately $9-15 \%$ of low income and $\mathrm{racial} /$ ethnic minority women during the perinatal period and as many as $25 \%$ throughout childrearing in the US. ${ }^{3-5}$ It is the leading cause of health burden among women of reproductive age from high, middle, and low-income countries. ${ }^{1,6}$ This impact is compounded by the myriad negative effects that depression has on infants and families. ${ }^{7-9}$ The majority of depression care in the US is delivered in primary care settings, which have been called the "de facto US mental health system."10 This is particularly true for low-income patients, who face access barriers to specialty mental health care. ${ }^{11,12}$

The collaborative care model (CoCM) for mental disorders is a complex intervention composed of a multidisciplinary team with significant clinical benefit and cost-effectiveness for the treatment of adult depression in primary ${ }^{13-16}$ and perinatal care. ${ }^{17,18}$ This model has been identified as critical to improving the mental health of the US population by the Centers for Medicare \& Medicaid Services which have promulgated billing codes for public insurance to support CoCM implementation. ${ }^{19}$ Key care processes of CoCM include: 1) a dedicated care manager on staff at the health center, 2) evidence-based systematic case finding using validated tools, 3) a patient registry to support patient management, 4) escalation of treatment intensity using a stepped-care approach with evidence-based treatments (pharmacologic and psychosocial), 5) regular case review of patients' progress by a psychiatric consultant, and 6) review of care quality metrics to identify areas to target in improvement efforts. ${ }^{14}$ These processes are supported by appropriate health information technology infrastructure. ${ }^{20,21}$ Despite the high level of evidence for the effectiveness of CoCM, it has not been widely implemented. ${ }^{14,22,23}$ Moreover, the success of CoCM implementation and sustainment for general adult populations, measured by fidelity and clinical patient benefit, is highly variable. ${ }^{24,25}$ The identification of tools and strategies which can increase the rate of 
effective implementation of this evidence-based model for depression in primary care settings has high potential to improve population behavioral health.

Organizational culture and climate have been proposed to influence the effective implementation and clinical outcomes of complex clinical interventions within agencies providing mental health services ${ }^{26,27}$ including primary care health centers. ${ }^{28}$ Glisson and colleagues define organizational culture as the shared expectations and behavioral norms that guide and direct providers' care-related behaviors within the organization, including the level of expectation that providers will: (a) prioritize responsiveness to patients' needs over competing organizational goals (e.g. optimization of billable units) and maintain competence in up-to-date treatment models (referred to as proficient culture), (b) maintain the status quo and resist new ways of working (referred to as resistant culture), and (c) adhere to centralized decisionmaking (referred to as rigid culture) ${ }^{29}$ This model defines organizational climate as providers' shared perceptions of the impact of the work environment on their personal well-being, including: the extent to which providers understand their role in the organization and receive the cooperation and support they need from colleagues and supervisors to perform their job well (functional climate), the extent to which providers are able to remain personally invested in their work (engaged climate), and the extent to which providers experience role conflict and role overload (stressful climate). Prior research has linked these dimensions of culture and climate to service outcomes in social service agencies ${ }^{30,31}$ and has shown that interventions targeting these dimensions are associated with improved social service outcomes. ${ }^{32,33}$ Furthermore, studies in specialty mental health settings have shown that therapists' use of evidencebased psychotherapy techniques is higher in clinics with more proficient cultures and more functional climates $^{34,35}$ and that these dimensions of culture and climate are related to practitioners' level of fidelity to evidence-based practice models in schools. ${ }^{36}$ This stream of research compliments a growing number of empirical studies linking variation in organizational culture and climate to variation in implementation outcomes, such as adoption of evidence-based practices and fidelity to evidence-based practice models. ${ }^{37-40}$

Despite the growing number of studies linking variation in organizational culture and climate to variation in implementation outcomes, a recent systematic review found few or no studies have tested whether variation in organizational culture and climate explain variation in the clinical outcomes of evidencebased practices implemented in primary care settings. ${ }^{37}$ This is an important knowledge gap given the centrality of clinical outcomes to the goals of implementation science. ${ }^{41}$ Assessing the clinical importance of culture and climate as constructs related to care improvement and their independence from other factors influencing implementation and outcomes is needed to guide further work in this area. Given evidence that culture and climate vary across primary care health centers which serve vulnerable populations, we wished to test whether this variation could help explain variation in patient clinical outcomes of the evidence-based CoCM for perinatal depression. ${ }^{28}$ We hypothesized that patients served by centers with more proficient cultures and more functional climates would experience superior clinical outcomes of CoCM. Evidence for this hypothesis would support organization-level strategies for the 
implementation and sustainment of complex, team-based interventions for common mental disorders and other chronic illnesses.

\section{Methods}

\section{Study Setting}

This study made use of clinical and survey data collected from July 2013 to July 2015 in the course of routine care of women participating in the High Risk Mothers program, a part of the Mental Health Integration Program of Washington State in the US. Funded by the State of Washington and King County and administered by the Community Health Plan of Washington State, this program provides behavioral health services for women in pregnancy and with children in thirteen community health centers (Federally Qualified Health Centers and Look-Alikes), in King County. Details of the program are described elsewhere but briefly, women in pregnancy or with children who are identified in participating health centers with elevated depression symptomatology are offered the team-based CoCM model. ${ }^{42,43}$ The interdisciplinary team caring for the patient consists of the primary care provider, a care manager, and a psychiatric consultant. In accordance with the CoCM model and quality metrics for depression care, treatment typically lasts 6 to 8 months and occurs in phases. ${ }^{44,45}$ During the initial diagnosis and treatment decision phase, interventions are selected and implemented based on the clinical assessment. During the acute care phase, treatment trials of different therapeutic modalities (non-pharmacologic and pharmacologic), treatment doses, and pharmacologic agents are applied until a significant improvement is seen. Response to treatment is monitored by assessing depression symptoms at intake and at every subsequent contact in order to guide care.

Clinical data used in this study (i.e., depression symptomology as described below) was collected via an internet-based electronic care management software system designed to support the delivery of CoCM. ${ }^{20}$ This system is utilized by care managers and data from the system have been used to evaluate outcomes in several previous studies of CoCM. ${ }^{42,43,46,47}$ The present study was reviewed and approved by the Institutional Review Board of the University of Washington.

\section{Independent and Dependent Variables}

Organizational culture and climate. The organizational culture and climate of participating health centers were assessed using the 105 -item Organizational Social Context (OSC) measure. ${ }^{29}$ The reliability, factor validity, criterion-related validity, and predictive validity of the OSC have been supported in numerous studies including two national studies in specialty mental health and child welfare settings, respectively, as well as randomized controlled trials. ${ }^{29-32,48-53}$

Organizational culture is defined by the OSC as the norms and expectations that govern the way work is done in an organization and is assessed along three dimensions of proficiency, rigidity, and resistance. ${ }^{29,30}$ Proficient organizational cultures are characterized by norms and expectations that 
clinicians will be responsive to client needs and maintain competence in up-to-date treatment practices. Rigid cultures are characterized by norms and expectations that clinicians will have limited flexibility and discretion in carrying out work tasks, minimal input into important management decisions, and high compliance with rules and regulations. Resistant cultures expect clinicians to maintain the status quo.

Organizational climate is defined by the OSC as clinicians' shared perceptions of the impact of the work environment on their personal well-being and is assessed along three dimensions of engagement, functionality, and stress. ${ }^{29,30}$ Clinicians in engaged climates perceive they are able to sustain personal concern for their clients and accomplish many personally meaningful goals in their work. Clinicians in functional climates perceive they receive the support and cooperation they need from colleagues to effectively do their job and have a clear understanding of their role and how it fits into the organization. Clinicians in stressful climates perceive they are overloaded in their work role and pulled in conflicting directions (role conflict). Alpha reliabilities for the six OSC dimensions in the present sample were as follows: proficiency $(a=0.90)$, rigidity $(a=0.68)$, resistance $(a=0.77)$, engagement $(a=0.80)$, functionality $(a=0.92)$, and stress $(a=0.92)$.

The OSC conceptualizes culture and climate as the shared perceptions of treatment team members; consequently, the perceptions of individuals who are directly involved in delivering care are the most informative for understanding how culture and climate influence treatment delivery. Thus, individual OSC surveys were administered to members of the clinical teams involved with the High Risk moms program at each participating health center. In order to ensure candid responses to the surveys, supervisors were not present when care team members completed surveys. Responses were collected by study staff who were not known to care team members personally and surveys were placed in sealed envelopes before leaving the survey locations.

In accordance with best practices, care team members' individual responses to the OSC were aggregated (i.e., averaged) to the health center level in order to measure health center culture and climate. ${ }^{54-56}$ Aggregation is guided by the use of composition models which describe how items must be worded in order to justify aggregation and establish empirical criteria for evaluating the construct validity of aggregated variables. ${ }^{56}$ Aggregation of individual scores to the center-level is justified when there is a high level of inter-rater agreement on each culture/climate dimension within each health center. We evaluated inter-rater agreement using the $r_{\mathrm{wg}(\mathrm{j})}$ index which ranges from 0 to 1 (higher values indicate greater agreement). ${ }^{57}$ A cutoff of 0.7 on the $r_{\mathrm{wg}(\mathrm{j})}$ index is recommended to support aggregation of individual culture/climate scores to the unit level. ${ }^{58,59}$ Examination of the $r_{\mathrm{wg}(\mathrm{j})}$ values for all 10 health centers in the sample on all six OSC dimensions indicated no values fell below $r_{\mathrm{wg}(\mathrm{j})}=0.91$. This provided a high level of support for clinicians' agreement on their perceptions of culture and climate within each center. Aggregate raw scores were converted to T scores based on a national sample of 100 mental health centers with $a=50$ and $\sigma=10 .{ }^{29}$ 
Depression symptom level. Patients' depression symptom level at intake and at each subsequent contact was assessed during usual clinical care using the Patient Health Questionnaire-9 (PHQ-9), a widely used instrument that is valid for use in pregnancy as well as a wide range of adult populations for screening and monitoring depression symptom change over time. ${ }^{60-62}$ Total scores are calculated by summing the 9 items. Using standard conventions, we made use of the cut score of 10 or above to identify women with likely depression and with moderate to severe symptom levels. ${ }^{61}$

\section{Control Variables}

Because of known associations with the primary independent and dependent variables, and in order to adjust models for differences across health centers, ${ }^{63,64}$ we included the following variables as covariates in all analyses: center size (number of patients served), patient ethnicity (Latina vs. not Latina), patient race (Black/African American vs. not Black/African American), patient age at enrollment into care, and patient history of prior psychiatric treatment as reported by the patient (yes/no). ${ }^{43}$ Because level of implementation support is associated with variation in patient outcomes at the site level among the clinics we included type of implementation support (i.e., Basic vs. Enhanced) as a control variable. While this is described in detail elsewhere, briefly Basic support included in person team training and access to implementation tools while Enhanced support added prolonged external practice facilitation. ${ }^{24}$

\section{Statistical Analysis}

As a preliminary analysis, we tested whether there was variation in rates of clinically significant improvement in PHQ-9 scores from baseline to 6.5 months post-baseline across health centers. This time period corresponds to standard quality metrics for depression care. ${ }^{44}$ Clinically significant improvement was defined using the Jacobson and Truax reliable and clinically significant change criterion $c$ which has performed well in other research. ${ }^{65}$ According to this criterion, patients were deemed to have achieved clinically significant improvement if their PHQ-9 Total Score improved by 6.76 points or more from baseline to their last follow-up and if their final follow-up score was below the clinical cutoff of 10 . Analysis of variance (ANOVA) tested whether health centers differed on the mean proportion of patients who achieved clinically significant improvement based on this criterion.

The relationships between health center culture and climate and growth in patients' depression symptoms from baseline to 6.5 months post-baseline were tested using three-level hierarchical linear models (HLM). ${ }^{63,66}$ Hierarchical linear models are ideal for longitudinal data that are clustered within health centers because they make use of all available measurements, generate unbiased parameter estimates when unobserved values are missing at random, adjust standard errors for nesting at both the patient and health center levels, and do not require uniform spacing of observations across patients. ${ }^{67}$ In the analyses, patients' PHQ-9 Total Score at intake and at each subsequent observation point was modeled as a function of growth parameters (time and time-squared) at level 1, patient characteristics at level 2, and health center characteristics (including culture or climate) at level 3 . Models incorporated random effects at the patient and health center levels to account for the nesting of time within patient 
and patient within health center. All patient and center covariates were grand mean centered to facilitate model interpretation and to adjust for differences across health centers in case mix. ${ }^{64}$ There were no missing data on health center characteristics or patient covariates included in the models. Models were estimated via maximum likelihood estimation in HLM 8 software. ${ }^{68}$ The models estimate the unique effect of each of the six dimensions of culture and climate on growth in patients' symptom scores for depression from baseline to 6.5 months post-baseline, over and above the effects of patient-level characteristics (i.e., patients' ethnicity, race, age at entry, and prior history of treatment), variation in patient characteristics across sites (i.e., case mix), center size, and type of implementation support. ${ }^{63}$

Separate models were estimated for each of the six dimensions of culture and climate in order to identify which dimensions were most closely associated with variation in clinical outcomes. The BenjaminiHochberg false discovery procedure was used to control for multiple comparisons. ${ }^{69}$ Concerns regarding multicollinearity prohibited estimation of a single model with multiple dimensions of culture and climate included simultaneously; ${ }^{70}$ the average correlation among the culture and climate dimensions was $r=$ 0.70 in this sample. As a sensitivity analysis, we tested the effects of each culture/climate dimension on growth in patients' depression symptoms with and without control variables and the results were substantively similar; consequently, only analyses with control variables are presented.

Preliminary analyses confirmed there was significant clustering of $\mathrm{PHQ}-9$ depression scores at the health center level $(\operatorname{ICC}(1)=0.09, p<0.001)$ and patient level $(\operatorname{ICC}(1)=0.36, p<0.001)$ and that growth in depression symptoms was best represented by a quadratic growth model at level 1 rather than by a linear growth model $\left(X^{2}=155.29, \mathrm{df}=1, \mathrm{p}<0.001\right)$. In quadratic growth models, change in symptoms is described by two parameters (1) the instantaneous growth rate (represented by the time parameter), which differs at each time point and indicates the direction and magnitude of change at that time (e.g., at baseline), and (2) the rate of acceleration (represented by the time-squared parameter), which remains constant across all time points and indicates the magnitude and direction of change in the rate of change across the entire study period. Significant associations between culture/climate and the rate of acceleration indicate that culture/climate explains variation in patients' overall change in depression from baseline to the study endpoint (6.5 months post-baseline). Significant associations between culture/climate and the instantaneous rate of change at a specific time point provide insight into when culture/climate begin to differentially influence depression outcomes (e.g., at 4 months post-baseline).

To facilitate interpretation of the model results, effect sizes were calculated representing the standardized mean difference in PHQ-9 Total Scores at 6.5-month post-baseline between patients served by health centers with high values of the culture/climate dimension (i.e., average of the upper quartile) versus patients served by health centers with low values of the culture/climate dimension (i.e., average of the lower quartile). ${ }^{71}$ The standardized mean difference is reported as a Cohen's $\mathrm{d}^{72}$ which is commonly interpreted as small $(\mathrm{d}=0.2)$, medium $(\mathrm{d}=0.5)$ and large $(\mathrm{d}=0.8)$. In addition, we calculated an adjusted Cohen's $d, d_{a d j i}{ }^{73}$ which represents the standardized mean difference between the groups in their change in PHQ-9 Total Score from baseline to 6.5 months post-baseline. 


\section{Results}

OSC surveys were collected from 13 FQHCs from June 2014 to September 2014. Survey results from clinical teams at $10 \mathrm{FQHCs}$ were included in the analyses because three teams did not have clinical outcome information during the study period. There were no differences in care team member characteristics between FQHCs included in the analyses versus those excluded $(p>0.05)$. Furthermore, there were no differences in care team member characteristics among the 10 clinics included in the study sample $(p>0.05)$. Table 1 presents characteristics of the FQHCs and care team members who were included in the study. Across FQHCs, the average number of care team members who responded to the OSC was 5.4 (range 3 to 9). Culture and climate scores for participating primary care health centers were consistent with national validation studies (see Table 2).

Change in depression symptoms, measured using the PHQ-9 total score, was assessed for 468 women in pregnancy or with children enrolled in the High Risk mothers' program in participating FQHCs from July 2013 to July 2015 (a year prior to administration of the OSC to one year after). Within the study period, a total of $N=675$ women had one or more episodes of care for depression at a participating FQHC. Of these, $n=207$ were excluded from analyses because their intake PHQ-9 score for the episode was less than the cut score of 10 , resulting in a total sample of $N=468$ women with $N=1,455$ PHQ-9 observations (average $N$ of observations per participant $=3.1, S D=2.4$ ). The average number of patients included in the analyses per health center was $n=46.8(S D=37.6)$. As is shown in Table 1 , the sample was comprised of women (mean age $=33$ years) of diverse race/ethnicity. The mean and range of initial depression symptomatology level (mean $=16.2, \mathrm{SD}=4.69$; range $=10-27$ ), included patients in the moderate (PHQ-9 score of 15-19) and severe (20-27) range; a high percentage of women reported suicidal ideation (28.2\%). There were significant differences among the 10 participating health centers on patients' mean age at baseline, proportion of patients of Latina ethnicity, proportion of patients of Black/African American race, and proportion of patients with a history of prior treatment $(P<.05)$; all of these were included as control variables in the analyses to adjust for differences in case mix.

\section{Variation in Clinical Outcomes across Health Centers}

On average, $42 \%$ of patients achieved clinically significant improvement in their PHQ-9 Total Score from baseline to their last follow-up based on the clinically significant improvement criterion described above. There was significant variation across health centers in their rates of clinically significant improvement, $F=2.39, d f=9,313, p=0.012$, with a range of $17 \%$ to $57 \%$ of patients improved at each health center.

\section{Association of Health Center Culture and Climate with Improvement in Depression}

Results of the hierarchical linear models testing the relationships between each dimension of culture/climate and growth in mothers' depression symptoms, adjusted for center characteristics, type of implementation support, and patient characteristics, indicated that two dimensions of culture/climate were related to significantly greater improvement in depression symptoms from baseline to the end of the 6.5-month period (see Table 3). Patients served by FQHCs with more proficient cultures improved 
significantly more from baseline to 6.5 months post-baseline than patients served by FQHCs with less proficient cultures $(B=-0.01, S E=0.00, p=0.020)$, resulting in a large effect size of $d=0.95(95 \% \mathrm{Cl}=$ 0.28 to 1.62) when comparing patients served by centers with highly proficient cultures (average of upper quartile) versus centers with less proficient cultures (average of lower quartile) at 6.5 months (see Figure 1). On average, patients served by health centers with highly proficient cultures improved by 5.08 points from baseline to 6.5 months post-baseline, compared to an average improvement of 0.14 points for patients served by centers with less proficient cultures. This represents a large difference in change scores of $d_{a d j}=0.78$. (95\% $\mathrm{Cl}=0.10$ to 1.45$)$.

Figure 1 shows the covariate-adjusted mean PHQ-9 Total Scores from baseline to 6.5 months postbaseline for patients served by centers with high versus low proficiency cultures. As is shown in the figure, on average, patients served by centers with highly proficient cultures recovered after four months (i.e., PHQ-9 Total Score $<10)$ and remained stabilized below the clinical cutoff of 10 at 6.5 months postbaseline $(M=9.71)$; however, patients served by centers with less proficient cultures improved after four months but then deteriorated to well above the clinical cutoff by 6.5 months post-baseline $(M=15.74)$. The instantaneous rate of change coefficients $\left(B_{7}\right)$ in Table 3 show exactly when outcomes began to diverge for patients served by clinics with more and less proficient cultures. Specifically, at 4 months postbaseline, patients served by clinics with less proficient cultures began deteriorating significantly faster than patients served by clinics with more proficient cultures $(B=-0.04, S E=0.02, p=0.041)-$ a trend that continued to the end of the study and resulted in the large difference in outcomes.

Patients served by FQHCs with more functional climates also improved significantly more from baseline to 6.5 months post-baseline than patients served by FQHCs with less functional climates $(b=-0.01, S E=$ $0.00, p=0.044)$, resulting in a large effect size of $d=0.81(95 \% \mathrm{Cl}=0.32$ to 1.31$)$ when comparing patients served by centers with low versus high functionality climates at 6.5 months post-baseline (see Figure 1). As is shown in Figure 1, after adjusting for covariates, patients served by centers with high functionality climates improved by 5.25 points on average compared to an improvement of 1.12 points among patients served by centers with low functionality climates. This resulted in a medium difference in change scores of $d_{a d j}=0.65(95 \% \mathrm{Cl}=0.16$ to 1.15$)$ at 6.5 months post-baseline. Similar to the results for proficient culture, patients served by centers with both high and low functionality climates improved on average from baseline to 4 months post-baseline; however, at 4 months post-baseline patients served by centers with less functional climates began experiencing significantly greater deterioration in depression symptoms compared to patients served by centers with more functional climates $(B=-0.03, S E=0.01, p=$ 0.037). By 6.5 months post-baseline, patients served by centers with highly functional climates remained below the clinical cutoff $(M=9.56)$ whereas patients served by centers with less functional climates were well above the clinical cutoff $(M=14.74)$. Both the effects of proficient culture and functional climate remained statistically significant after adjusting for multiple comparisons using the Benjamini-Hochberg procedure with a false discovery rate of 0.15 .

\section{Discussion}


In this study of clinical outcomes for economically vulnerable patients with maternal depression treated by the evidence-based CoCM in 10 primary care health centers, we found that depression outcomes varied significantly by center. An assessment of health center culture and climate was associate with this variation in patients' improvement in clinical depression from baseline to 6.5 months post-baseline independent of other factors known to be associated with this variation including level of implementation support. ${ }^{25}$ Specifically, at 6.5-months post-baseline, patients who received the CoCM in primary care health centers with highly proficient cultures improved in their depression symptoms on average by 5.08 points compared to an average improvement of only 0.14 points among patients served by centers with less proficient cultures. This resulted in a large adjusted effect size of $d=0.78$. Patients served by centers with more functional climates also exhibited greater improvement in their depression symptoms at 6.5 months post-baseline, resulting in a medium adjusted effect size of $d=0.65$ when compared to patients served by centers with less functional climates. These results support the hypothesis that organizational culture and climate independently contribute to variation in the clinical outcomes of CoCM for depression as implemented in primary care health centers. These findings offer some of the first evidence linking organizational culture and climate to variation in the clinical outcomes of evidence-based practices implemented in primary care. Given the prominence of culture and climate within implementation frameworks, these findings represent an important advance for implementation theory and practice.

Importantly, patients served by centers with more proficient cultures and more functional climates only began exhibiting superior clinical outcomes at four months post-baseline. Prior to four months, patients in all centers improved, on average, to depression levels below the clinical cutoff; however, beginning at four months post-baseline, patients served by centers with less proficient cultures and less functional climates began to worsen significantly even as their peers continued to improve or worsened at a significantly slower rate. This resulted in a large difference in depression outcomes at 6.5 months postbaseline: patients in centers with more proficient cultures and more functional climates remained at or below the clinical cutoff, whereas their peers in centers with less proficient cultures and less functional climates were well above the clinical cutoff and thus had worse depression outcomes. The medium to large effect sizes observed in this study provide exciting evidence suggesting that culture and climate plays a role in shaping not only the implementation but also the clinical effectiveness of evidence-based practices implemented in routine care settings. Further work is needed to identify the mechanism for this difference but CoCM relies on systematic proactive and sustained follow up of patients to ensure sustained improvement and it is plausible that this varies by health center culture and climate.

Studies have posited that organizational culture and climate influence practice change and the implementation of effective interventions in health care; however, little previous work has tested the association of organizational culture and climate with variation in the clinical outcomes of evidencebased practices implemented in primary care. In one study of six FQHCs similar to those included in the current research, qualitative assessments supported the construct validity of the culture and climate dimensions assessed by the OSC and also showed that health centers varied in their cultures and climates. ${ }^{28} \mathrm{~A}$ high level of variation in clinical outcomes across sites that implement CoCM has been 
found. ${ }^{25}$ We have extended this work by showing that two OSC dimensions (proficient culture and functional climate) are associated with variation in clinical outcomes of patients independent of other factors known to be associated with this variation. .

Most studies of variation in clinical outcomes of CoCM have focused on patient-level characteristics or policy interventions to incentivize care delivery as predictors. ${ }^{42,43}$ The health centers included in our study varied in the rates of clinically significant patient improvement by approximately three fold, from $17 \%$ to $57 \%$, showing the need to look at health center-level factors influencing outcomes for this complex intervention for chronic disease. Given the difficulty of implementing $\mathrm{CoCM}$, including creating new clinical relationships and workflows across distinct providers and staff, it is not surprising that patient improvement was associated with health center-level measures of culture and climate even after adjusting for a range of patient and health center characteristics including case mix. A high level of organizational support is needed to carry out the practice changes required to implement and sustain CoCM.

The identification of an association between proficient culture and variation in the clinical outcomes of CoCM for depression is consistent with preliminary research showing that proficient culture explains variation in implementation outcomes such as evidence-based practice adoption across community healthcare organizations. ${ }^{34}$ This finding is also consistent with the substantive focus of proficient culture which addresses the extent to which treatment providers perceive they are expected to prioritize patient well-being and maintain competence in effective treatment models above competing organizational priorities. Such norms and expectations likely prompt, support, and reinforce care team members for embracing new evidence-based practices such as CoCM, developing expertise in their use, and applying them in a responsive manner that contributes to patient well-being. Relatedly, clinicians in functional climates perceive that they receive the support and cooperation they need from colleagues to effectively do their job and have a clear understanding of their role and how it fits into the organization's larger mission. Proficient culture and functional climate are also most closely related to implementation outcomes for evidence-based practices in other settings. ${ }^{36,38}$

Results from this study suggest that the implementation of evidence-based practices such as CoCM for depression may be improved by implementation strategies that generate proficient cultures and functional climates. Glisson and colleagues have shown that proficient cultures and functional climates can be generated in social service and specialty mental health organizations through organizational interventions that engage treatment staff in collaborative monitoring of quality and outcomes to identify and remove service barriers. ${ }^{32,52,53,74}$ However, there are likely many strategies that can contribute to proficient cultures and functional climates within health care organizations and research is needed to develop and test implementation strategies that act on these targets. ${ }^{75}$

While the current study supports the linkage between health center culture and climate and variation in patient outcomes of $\mathrm{CoCM}$, there are a number of limitations. First, this is an observational study that does not provide a basis for causal inference. Clinical outcomes of CoCM are undoubtedly influenced by 
many factors and it was not possible to control for all of these variables in the present study. Additional research that replicates these findings and rules out alternative confounds-perhaps by including organizational culture and climate as a treatment moderator in an implementation-effectiveness trial of CoCM for depression-is needed. In addition, the OSC measure was assessed at one time in the middle of the study period which raises issues related to temporality. Although the measurement of culture/climate did not precede all measurements of patients' clinical outcomes in time, there is evidence that culture and climate can be stable in the absence of intervention; consequently, we believe an argument can be made that the cultures and climates of these clinics were in place prior to the actual measurement period and remained in place during the months following measurement. Furthermore, the use of a single measurement may actually increase the robustness of the results as remote measurement of culture/climate relative to clinical outcomes should reduce (not increase) the likelihood of statistically significant relations between these variables. Further, while the results of this study must be limited to the patient population and health centers included in the sample, we believe these findings are likely to generalize to patients with common mental disorders and other chronic diseases. The evidence-based principles of effective chronic care of diseases are reflected in the CoCM and likely apply to other disorders. Finally, the study included a small health center sample $(\mathrm{N}=10)$ and a relatively small patient sample $(\mathrm{N}=468)$; larger studies are needed to confirm this work.

\section{Conclusions}

The current study tested whether variation in clinical outcomes of CoCM as implemented in primary care health centers could be in part explained by variation in the centers' cultures and climates. We found that parenting women with depression were more likely to experience clinical improvement and maintain this improvement if they were treated in health centers with higher levels of proficient culture and functional climate independent of center,patient, and other implmentation covariates associated with outcomes. Because of evidence that interventions targeting organizational culture and climate support improved outcomes in other contexts $32,33,76$, it will be important to explore whether similar interventions can improve depression outcomes and reduce their variation in health centers. Additional research is also needed to determine if differences in fidelity and sustainment of CoCM for depression can be explained by organizational measures of culture and climate.

\section{Abbreviations}

CoCM: Collaborative care model

ICC: Intraclass correlation coefficient

OSC: Organizational social context

PHQ-9: Patient health questionnaire-9 


\section{Declarations}

Ethics approval and consent to participate: This study was reviewed and approved by the Institutional Review Board of the University of Washington.

Consent for publication: Not applicable

Availability of data and materials: The dataset used and/or analyzed for this study are available from Dr. lan Bennett (ibennett@uw.edu) on reasonable request.

Competing interests: The authors declare that they have no competing interests.

Funding: Funding for the work presented in this paper was provided in part by the Washington University Implementation Research Institute (Bennett) and the Eitel Foundation (Unützer). These funding bodies had no role in the design of the study, data collection, analysis, or interpretation, or writing the manuscript.

Authors' contributions: IMB conceived and oversaw the overall study, including conceptualization of the study hypotheses, interpreting the data, writing the manuscript, editing the manuscript, and securing funding for the study. NJW led the conceptualization of study hypotheses, analyzed and interpreted the data, and led the writing of the manuscript. JR contributed to data analysis and interpretation as well as editing the manuscript. TG, PG, EP, and AB contributed to conceptualizing the study, interpreting the data, and editing the manuscript. JU obtained funding for this research and contributed to study design and editing the manuscript. All authors read and approved the final manuscript.

Reporting Standards: The Standards for Reporting Implementation Studies (StaRI) checklist was followed in preparation of this manuscript.

Acknowledgements: Not applicable

\section{References}

1. Whiteford HA, Degenhardt L, Rehm J, Baxter AJ, Ferrari AJ, Erskine HE, et al. Global burden of disease attributable to mental and substance use disorders: findings from the Global Burden of Disease Study 2010. The Lancet. 2013;382:1575-86.

2. Greenberg PE, Fournier A-A, Sisitsky T, Pike CT, Kessler RC. The economic burden of adults with major depressive disorder in the United States (2005 and 2010). J Clin Psychiatry. 2015;76:155-62.

3. Vesga-López O, Blanco C, Keyes K, Olfson M, Grant BF, Hasin DS. Psychiatric disorders in pregnant and postpartum women in the United States. Arch Gen Psychiatry. 2008;65:805-15.

4. Gaynes BN, Gavin N, Meltzer-Brody S, Lohr KN, Swinson T, Gartlehner G, et al. Perinatal depression: prevalence, screening accuracy, and screening outcomes. Evid Rep Technol Assess (Summ). 2005;18. 
5. Melville JL, Gavin A, Guo Y, Fan M-Y, Katon WJ. Depressive disorders during pregnancy: prevalence and risk factors in a large urban sample. Obstet Gynecol. 2010;116:1064-70.

6. Ferrari AJ, Norman RE, Freedman G, Baxter AJ, Pirkis JE, Harris MG, et al. The burden attributable to mental and substance use disorders as risk factors for suicide: findings from the Global Burden of Disease Study 2010. PloS One. 2014;9:e91936.

7. Stein A, Pearson RM, Goodman SH, Rapa E, Rahman A, McCallum M, et al. Effects of perinatal mental disorders on the fetus and child. The Lancet. 2014;384:1800-19.

8. Pilowsky DJ, Wickramaratne PJ, Rush AJ, Hughes CW, Garber J, Malloy E, et al. Children of currently depressed mothers: a STAR*D ancillary study. J Clin Psychiatry. 2006;67:126-36.

9. Bennett IM, Schott W, Krutikova S, Behrman JR. Maternal mental health, and child growth and development, in four low-income and middle-income countries. J Epidemiol Community Health. 2016;70:168-73.

10. Regier DA, Narrow WE, Rae DS, Manderscheid RW, Locke BZ, Goodwin FK. The de facto US mental and addictive disorders service system. Epidemiologic catchment area prospective 1-year prevalence rates of disorders and services. Arch Gen Psychiatry. 1993;50:85-94.

11. Bennett IM, Marcus SC, Palmer SC, Coyne JC. Pregnancy-related discontinuation of antidepressants and depression care visits among Medicaid recipients. Psychiatr Serv. 2010;61:386-91.

12. Bennett IM, Palmer S, Marcus S, Nicholson JM, Hantsoo L, Bellamy S, et al. "One end has nothing to do with the other:" patient attitudes regarding help seeking intention for depression in gynecologic and obstetric settings. Arch Womens Ment Health. 2009;12:301-8.

13. Unutzer J, Katon WJ, Fan M-Y, Schoenbaum MC, Lin EHB, Della Penna RD, et al. Long-term cost effects of collaborative care for late-life depression. Am J Manag Care. 2008;14:95-100.

14. Katon W, Unutzer J, Wells K, Jones L. Collaborative depression care: history, evolution and ways to enhance dissemination and sustainability. Gen Hosp Psychiatry. 2010;32:456-64.

15. Gilbody S, Bower P, Fletcher J, Richards D, Sutton AJ. Collaborative care for depression: a cumulative meta-analysis and review of longer-term outcomes. Arch Intern Med. 2006;166:2314-21.

16. Gilbody S, Bower P, Whitty P. Costs and consequences of enhanced primary care for depression: systematic review of randomised economic evaluations. Br J Psychiatry. 2006;189:297-308.

17. Melville JL, Reed SD, Russo J, Croicu CA, Ludman E, LaRocco-Cockburn A, et al. Improving care for depression in obstetrics and gynecology: a randomized controlled trial. Obstet Gynecol. 2014;123:1237-46.

18. Wells KB, Miranda J, Gonzalez JJ. Overcoming barriers and creating opportunities to reduce burden of affective disorders: a new research agenda: introduction. Ment Health Serv Res. 2002;4:175-8.

19. Liao JM, Navathe AS, Press MJ. Medicare's approach to paying for services that promote coordinated care. JAMA. 2019;321:147-8.

20. Unutzer J, Choi Y, Cook IA, Oishi S. A web-based data management system to improve care for depression in a multicenter clinical trial. Psychiatr Serv. 2002;53:671-3, 678. 
21. Bauer AM, Thielke SM, Katon W, Unutzer J, Arean P. Aligning health information technologies with effective service delivery models to improve chronic disease care. Prev Med. 2014;66:167-72.

22. Katon W, Unutzer J. Collaborative care models for depression: time to move from evidence to practice. Arch Intern Med. 2006;166:2304-6.

23. Unutzer J. Evidence-based treatments for anxiety and depression: lost in translation? Depress Anxiety. 2008;25:726-9.

24. Solberg LI, Crain AL, Jaeckels N, Ohnsorg KA, Margolis KL, Beck A, et al. The DIAMOND initiative: implementing collaborative care for depression in 75 primary care clinics. Implement Sci IS. 2013;8:135.

25. Unützer J, Carlo AC, Arao R, Vredevoogd M, Fortney J, Powers D, et al. Variation in the effectiveness of collaborative care for depression: does it matter where you get your care? Health Aff (Millwood). 2020;39:1943-50.

26. Woolston JL. Implementing evidence-based treatments in organizations. J Am Acad Child Adolesc Psychiatry. 2005;44:1313-6.

27. Glisson C, Williams NJ. Assessing and changing organizational social contexts for effective mental health services. Annu Rev Public Health. 2015;36:507-23.

28. Kramer TL, Drummond KL, Curran GM, Fortney JC. Assessing culture and climate of federally qualified health centers: a plan for implementing behavioral health interventions. J Health Care Poor Underserved. 2017;28:973-87.

29. Glisson C, Landsverk J, Schoenwald S, Kelleher K, Hoagwood KE, Mayberg S, et al. Assessing the organizational social context (OSC) of mental health services: implications for research and practice. Adm Policy Ment Health. 2008;35:98-113.

30. Glisson C, Green P. Organizational climate, services, and outcomes in child welfare systems. Child Abuse Negl. 2011;35:582-91.

31. Williams NJ, Glisson C. Testing a theory of organizational culture, climate and youth outcomes in child welfare systems: a United States national study. Child Abuse Negl. 2014;38:757-67.

32. Glisson C, Hemmelgarn A, Green P, Williams NJ. Randomized trial of the Availability, Responsiveness and Continuity (ARC) organizational intervention for improving youth outcomes in community mental health programs. J Am Acad Child Adolesc Psychiatry. 2013;52:493-500.

33. Glisson C, Schoenwald SK, Hemmelgarn A, Green P, Dukes D, Armstrong KS, et al. Randomized trial of MST and ARC in a two-level EBT implementation strategy. J Consult Clin Psychol. 2010;78:537-50.

34. Beidas RS, Williams NJ, Becker-Haimes EM, Aarons GA, Barg FK, Evans AC, et al. A repeated crosssectional study of clinicians' use of psychotherapy techniques during 5 years of a system-wide effort to implement evidence-based practices in Philadelphia. Implement Sci. 2019;14:67.

35. Williams NJ, Ehrhart MG, Aarons GA, Marcus SC, Beidas RS. Linking molar organizational climate and strategic implementation climate to clinicians' use of evidence-based psychotherapy techniques: cross-sectional and lagged analyses from a 2-year observational study. Implement Sci IS. 2018;13:85. 
36. Williams NJ, Frank HE, Frederick L, Beidas RS, Mandell DS, Aarons GA, et al. Organizational culture and climate profiles: relationships with fidelity to three evidence-based practices for autism in elementary schools. Implement Sci. 2019;14:15.

37. Li S-A, Jeffs L, Barwick M, Stevens B. Organizational contextual features that influence the implementation of evidence-based practices across healthcare settings: a systematic integrative review. Syst Rev. 2018;7:72.

38. Williams N, Glisson C. Changing organizational social context to support evidence-based practice implementation: a conceptual and empirical review. In: Albers B, Shlonsky A, Mildon R, editors. Implementation science 3.0. New York: Springer; 2020. p.145-172.

39. Smith SN, Almirall D, Prenovost K, Goodrich DE, Abraham KM, Liebrecht C, et al. Organizational culture and climate as moderators of enhanced outreach for persons with serious mental illness: results from a cluster-randomized trial of adaptive implementation strategies. Implement Sci IS. 2018;13:93.

40. Proctor E, Silmere H, Raghavan R, Hovmand P, Aarons G, Bunger A, et al. Outcomes for implementation research: conceptual distinctions, measurement challenges, and research agenda. Adm Policy Ment Health. 2011;38:65-76.

41. Eccles MP, Mittman BS. Welcome to implementation science. Implement Sci. 2006;1:1.

42. Bauer AM, Azzone V, Alexander L, Goldman HH, Unutzer J, Frank RG. Are patient characteristics associated with quality of depression care and outcomes in collaborative care programs for depression? Gen Hosp Psychiatry. 2012;34:1-8.

43. Huang H, Chan YF, Katon W, Tabb K, Sieu N, Bauer AM, et al. Variations in depression care and outcomes among high-risk mothers from different racial/ethnic groups. Fam Pr. 2012;29:394-400.

44. HEDIS Depression Measures for Electronic Clinical Data [Internet]. NCQA. [cited 2020 Nov 22]. Available from: https://www.ncqa.org/hedis/the-future-of-hedis/hedis-depression-measures-forelectronic-clinical-data/

45. Croghan TW, Schoenbaum M, Sherbourne CD, Koegel P. A framework to improve the quality of treatment for depression in primary care. Psychiatr Serv. 2006;57:623-30.

46. Huang H, Russo J, Bauer AM, Chan YF, Katon W, Hogan D, et al. Depression care and treatment in a chronically ill Medicare population. Gen Hosp Psychiatry. 2013;35:382-6.

47. Ratzliff AD, Ni K, Chan YF, Park M, Unutzer J. A collaborative care approach to depression treatment for Asian Americans. Psychiatr Serv. 2013;64:487-90.

48. Glisson C, Green P, Williams NJ. Assessing the Organizational Social Context (OSC) of child welfare systems: implications for research and practice. Child Abuse Negl. 2012;36:621-32.

49. Williams NJ, Glisson C. Reducing turnover is not enough: the need for proficient organizational cultures to support positive youth outcomes in child welfare. Child Youth Serv Rev. 2013;35.

50. Williams NJ, Beidas RS. Navigating the storm: how proficient organizational culture promotes clinician retention in the shift to evidence-based practice. PLoS ONE [Internet]. 2018 [cited 2020 Nov 22];13. Available from: https://www.ncbi.nlm.nih.gov/pmc/articles/PMC6303097/ 
51. Olin SS, Williams N, Pollock M, Armusewicz K, Kutash K, Glisson C, et al. Quality indicators for family support services and their relationship to organizational social context. Adm Policy Ment Health. 2014;41:43-54.

52. Williams NJ, Glisson C, Hemmelgarn A, Green P. Mechanisms of change in the ARC organizational strategy: increasing mental health clinicians' EBP adoption through improved organizational culture and capacity. Adm Policy Ment Health. 2017;44:269-83.

53. Glisson C, Williams NJ, Hemmelgarn A, Proctor E, Green P. Increasing clinicians' EBT exploration and preparation behavior in youth mental health services by changing organizational culture with ARC. Behav Res Ther. 2016;76:40-6.

54. Klein KJ, Dansereau F, Hall RJ. Levels issues in theory development, data collection, and analysis. Acad Manage Rev. 1994;19:195-229.

55. Rousseau DM. Issues of level in organizational research: multi-level and cross-level perspectives. Res Organ Behav. 1985;7:1-37.

56. Chan D. Functional relations among constructs in the same content domain at different levels of analysis: a typology of composition models. J Appl Psychol. 1998;83:234-246.

57. James LR, Demaree RG, Wolf G. rwg: an assessment of within-group interrater agreement. J Appl Psychol. 1993;78:306-9.

58. Bliese PD. Within-group agreement, non-independence, and reliability: Implications for data aggregation and analysis. In: Multilevel theory, research, and methods in organizations: foundations, extensions, and new directions. San Francisco, CA, US: Jossey-Bass; 2000. p. 349-81.

59. LeBreton JM, Senter JL. Answers to 20 questions about interrater reliability and interrater agreement. 2008;11:815-52.

60. Gjerdingen D, Crow S, McGovern P, Miner M, Center B. Postpartum depression screening at well-child visits: validity of a 2-question screen and the PHQ-9. Ann Fam Med. 2009;7:63-70.

61. Kroenke K, Spitzer RL, Williams JB. The PHQ-9: validity of a brief depression severity measure. J Gen Intern Med. 2001;16:606-13.

62. Spitzer RL, Williams JB, Kroenke K, Hornyak R, McMurray J. Validity and utility of the PRIME-MD patient health questionnaire in assessment of 3000 obstetric-gynecologic patients: the PRIME-MD Patient Health Questionnaire Obstetrics-Gynecology Study. Am J Obstet Gynecol. 2000;183:759-69.

63. Raudenbush SW, Bryk AS. Hierarchical linear models: applications and data analysis methods. SAGE; 2002.

64. Hofmann DA, Gavin MB. Centering decisions in hierarchical linear models: Implications for research in organizations. J Manag. 1998;24:623-41.

65. McMillan D, Gilbody S, Richards D. Defining successful treatment outcome in depression using the PHQ-9: a comparison of methods. J Affect Disord. 2010;127:122-9.

66. Hedeker D, Gibbons RD. Longitudinal data analysis. John Wiley \& Sons; 2006. 
67. Verbeke G, Molenberghs G. Linear mixed models for longitudinal data. Springer Science \& Business Media; 2009.

68. Raudenbush SW, Bryk T, Congdon R. HLM 8: Hierarchical linear and nonlinear modeling. Scientific Software International; 2004.

69. Benjamini Y, Hochberg Y. Controlling the false discovery rate: a practical and powerful approach to multiple testing. J R Stat Soc Ser B Methodol. 1995;57:289-300.

70. Yu H, Jiang S, Land KC. Multicollinearity in hierarchical linear models. Soc Sci Res. 2015;53:118-36.

71. Feingold A. Time-varying effect sizes for quadratic growth models in multilevel and latent growth modeling. Struct Equ Model Multidiscip J. 2019;26:418-29.

72. Cohen J. Statistical power analysis for the behavioral sciences. Routledge; 1977.

73. Durlak JA. How to select, calculate, and interpret effect sizes. J Pediatr Psychol. 2009;34:917-28.

74. Glisson C, Hemmelgarn A, Green P, Dukes D, Atkinson S, Williams NJ. Randomized trial of the Availability, Responsiveness, and Continuity (ARC) organizational intervention with communitybased mental health programs and clinicians serving youth. J Am Acad Child Adolesc Psychiatry. 2012;51:780-7.

75. Berry L, Seltman K. The Mayo clinic way: a story of cultural strength and sustainability. In: The Oxford handbook of organizational climate and culture. New York, NY: Oxford University Press; $p$. 603-19.

76. Glisson C, Williams NJ, Hemmelgarn A, Proctor E, Green P. Aligning organizational priorities with ARC to improve youth mental health service outcomes. J Consult Clin Psychol. 2016;84:713-725

\section{Tables}

Table 1. Characteristics of Participating FQHCs, Care Team Members, and Patients 


\begin{tabular}{|c|c|c|c|c|}
\hline Characteristic & Mean $(M)$ & $S D(\%)$ & Min & Max \\
\hline \multicolumn{5}{|l|}{ Care Team Members $(N=54)$} \\
\hline Years of experience & 19.06 & 11.39 & 2 & 40 \\
\hline Years in current health center & 9.41 & 7.75 & 1 & 33 \\
\hline Age in years & 46.73 & 12.55 & 25 & 67 \\
\hline \multicolumn{5}{|l|}{ Position } \\
\hline Direct care provider & 28 & 51.9 & & \\
\hline Supervisor & 8 & 14.8 & & \\
\hline Management & 4 & 7.4 & & \\
\hline Other (e.g., Quality Improvement Officer) & 10 & 18.5 & & \\
\hline \multicolumn{5}{|l|}{ Highest Education Completed } \\
\hline High school graduate & 3 & 5.6 & & \\
\hline Associate degree & 6 & 11.1 & & \\
\hline Bachelor's degree & 11 & 20.4 & & \\
\hline Master's degree & 15 & 27.8 & & \\
\hline Doctoral degree & 19 & 35.2 & & \\
\hline \multicolumn{5}{|l|}{ Race } \\
\hline Asian & 7 & 13.0 & & \\
\hline Black or African American & 2 & 3.7 & & \\
\hline White & 33 & 61.1 & & \\
\hline Other & 9 & 16.6 & & \\
\hline More than one race & 3 & 5.6 & & \\
\hline Hispanic/Latino(a) & 12 & 22.2 & & \\
\hline Female & 46 & 85.2 & & \\
\hline \multicolumn{5}{|l|}{ Patients $(N=468)$} \\
\hline Age in years & 33.47 & 8.39 & 15 & 69 \\
\hline PHQ-9 total score at baseline & 16.21 & 4.69 & 10 & 27 \\
\hline Endorsed suicidal ideation (PHQ item 9) & 132 & 28.2 & & \\
\hline Prior history of psychiatric treatment & 135 & 28.8 & & \\
\hline
\end{tabular}




\begin{tabular}{|llc|}
\hline Hispanic/Latina & 223 & 47.6 \\
\hline American Indian/Alaskan Native & \multicolumn{2}{l|}{} \\
\hline Asian & \multicolumn{2}{l|}{0.4} \\
\hline Black or African American & 47 & 9.4 \\
\hline Native Hawaiian or Other Pacific Islander & 5 & 10.0 \\
\hline White & 109 & 23.3 \\
\hline More than one race & 40 & 8.5 \\
\hline Unknown or Not Reported & 221 & 47.2 \\
\hline
\end{tabular}

\begin{tabular}{|lllll|}
\hline \multicolumn{4}{|l|}{ Table 2. Organizational Social Context Scale Measures for Health Centers $(\boldsymbol{N}=10)$} \\
\hline T scores & Mean $(\boldsymbol{N})$ & $\boldsymbol{S}(\%)$ & Min & Max \\
\hline Proficient culture $(\mu=50, \sigma=10)$ & 54.32 & 12.05 & 30.70 & 70.67 \\
\hline Rigid culture $(\mu=50, \sigma=10)$ & 56.26 & 6.40 & 44.57 & 65.16 \\
\hline Resistant culture $(\mu=50, \sigma=10)$ & 58.59 & 11.00 & 40.22 & 73.64 \\
\hline Engaged climate $(\mu=50, \sigma=10)$ & 53.92 & 14.31 & 26.84 & 74.08 \\
\hline Functional climate $(\mu=50, \sigma=10)$ & 64.99 & 11.81 & 43.99 & 82.21 \\
\hline Stressful climate $(\mu=50, \sigma=10)$ & 52.15 & 9.64 & 38.63 & 66.69 \\
\hline
\end{tabular}

Table 3. Effects of Culture and Climate on Change in Depression Symptoms (PHQ-9 Total Score) 


\begin{tabular}{|c|c|c|c|c|c|c|}
\hline \multirow[t]{2}{*}{$\begin{array}{l}\text { Culture/Climate } \\
\text { Dimension }\end{array}$} & \multicolumn{3}{|c|}{$\begin{array}{l}\text { Effect on Instantaneous Growth } \\
\text { Rate at Time } t_{i}\end{array}$} & \multicolumn{3}{|c|}{$\begin{array}{l}\text { Effect on Rate of Acceleration across } \\
\text { Times } t_{0}-t_{4}\end{array}$} \\
\hline & $B_{1}$ & $S E$ & $p$ & $B_{2}$ & $S E$ & $p$ \\
\hline \multicolumn{7}{|l|}{ Proficient Culture } \\
\hline Baseline $\left(t_{0}\right)$ & 0.05 & 0.03 & 0.118 & $-0.01 *$ & 0.00 & 0.020 \\
\hline 2-months $\left(t_{1}\right)$ & 0.00 & 0.01 & 0.791 & & & \\
\hline 4-months $\left(t_{2}\right)$ & $-0.04^{*}$ & 0.02 & 0.041 & & & \\
\hline 6-months $\left(t_{3}\right)$ & $-0.09 *$ & 0.04 & 0.043 & & & \\
\hline 6.5-months $\left(t_{4}\right)$ & $-0.10 *$ & 0.04 & 0.044 & & & \\
\hline \multicolumn{7}{|l|}{ Rigid Culture } \\
\hline Baseline $\left(t_{0}\right)$ & 0.06 & 0.04 & 0.228 & -0.00 & 0.01 & 0.542 \\
\hline 2-months $\left(t_{7}\right)$ & 0.03 & 0.02 & 0.059 & & & \\
\hline 4-months $\left(t_{2}\right)$ & 0.02 & 0.03 & 0.504 & & & \\
\hline 6 -months $\left(t_{3}\right)$ & -0.00 & 0.05 & 0.995 & & & \\
\hline 6.5-months $\left(t_{4}\right)$ & -0.00 & 0.06 & 0.941 & & & \\
\hline \multicolumn{7}{|l|}{ Resistant Culture } \\
\hline Baseline $\left(t_{0}\right)$ & 0.02 & 0.03 & 0.574 & 0.00 & 0.00 & 0.750 \\
\hline 2-months $\left(t_{1}\right)$ & 0.02 & 0.01 & 0.075 & & & \\
\hline 4-months $\left(t_{2}\right)$ & 0.03 & 0.02 & 0.124 & & & \\
\hline 6 -months $\left(t_{3}\right)$ & 0.03 & 0.03 & 0.348 & & & \\
\hline 6.5-months $\left(t_{4}\right)$ & 0.04 & 0.04 & 0.385 & & & \\
\hline \multicolumn{7}{|l|}{ Engaged Climate } \\
\hline Baseline $\left(t_{0}\right)$ & 0.01 & 0.02 & 0.552 & -0.01 & 0.00 & 0.123 \\
\hline 2-months $\left(t_{1}\right)$ & -0.01 & 0.01 & 0.249 & & & \\
\hline 4-months $\left(t_{2}\right)$ & $-0.04^{\star}$ & 0.01 & 0.037 & & & \\
\hline 6-months $\left(t_{3}\right)$ & -0.06 & 0.03 & 0.076 & & & \\
\hline
\end{tabular}




\begin{tabular}{|lllllll|}
\hline 6.5-months $\left(t_{4}\right)$ & -0.07 & 0.03 & 0.083 & & & \\
\hline Functional Climate & & & & & & \\
Baseline $\left(t_{0}\right)$ & 0.03 & 0.02 & 0.223 & 0.00 & 0.044 \\
\hline 2-months $\left(t_{7}\right)$ & -0.00 & 0.01 & 0.830 & & & \\
\hline 4-months $\left(t_{2}\right)$ & $-0.03^{*}$ & 0.01 & 0.037 & & & \\
\hline 6-months $\left(t_{3}\right)$ & -0.07 & 0.03 & 0.053 & & \\
\hline 6.5-months $\left(t_{4}\right)$ & -0.07 & 0.03 & 0.055 & & \\
\hline Stressful Climate & & & & & \\
\hline Baseline $\left(t_{0}\right)$ & 0.01 & 0.03 & 0.789 & 0.00 & \\
\hline 2-months $\left(t_{7}\right)$ & 0.02 & 0.01 & 0.111 & & \\
\hline 4-months $\left(t_{2}\right)$ & 0.04 & 0.02 & 0.111 & & \\
\hline 6-months $\left(t_{3}\right)$ & 0.05 & 0.04 & 0.265 & & \\
\hline 6.5-months $\left(t_{4}\right)$ & 0.05 & 0.04 & 0.290 & \\
\hline
\end{tabular}

Note: Coefficients were estimated using 3-level hierarchical linear models with time points $(N=1,455)$ nested within patients $(N=468)$ nested within health centers $(K=10)$. All models control for center size, level of implementation support, patient age at baseline, race, ethnicity, and prior history of psychiatric treatment. Statistically significant $B_{1}$ coefficients indicate culture/climate had an effect on patients' instantaneous growth rate in depression at that specific time $t_{i}$, negative coefficients indicate greater improvement in depression. Statistically significant $B_{2}$ coefficients indicate culture/climate had an effect on patients' overall acceleration, or change, in depression across the entire study period; negative coefficients indicate greater improvement from baseline to the study endpoint.

${ }^{*} p<0.05$

\section{Figures}




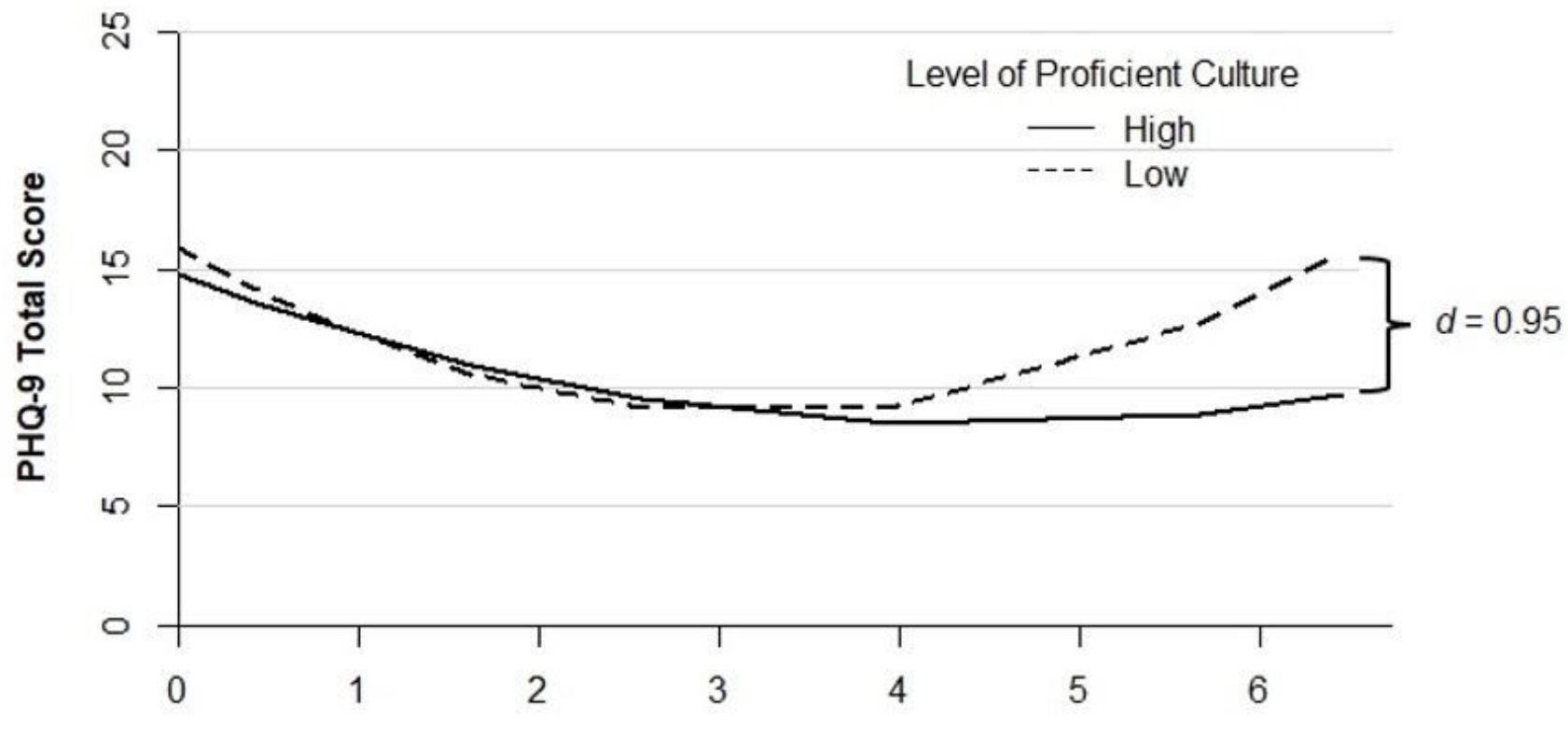

Months in Treatment

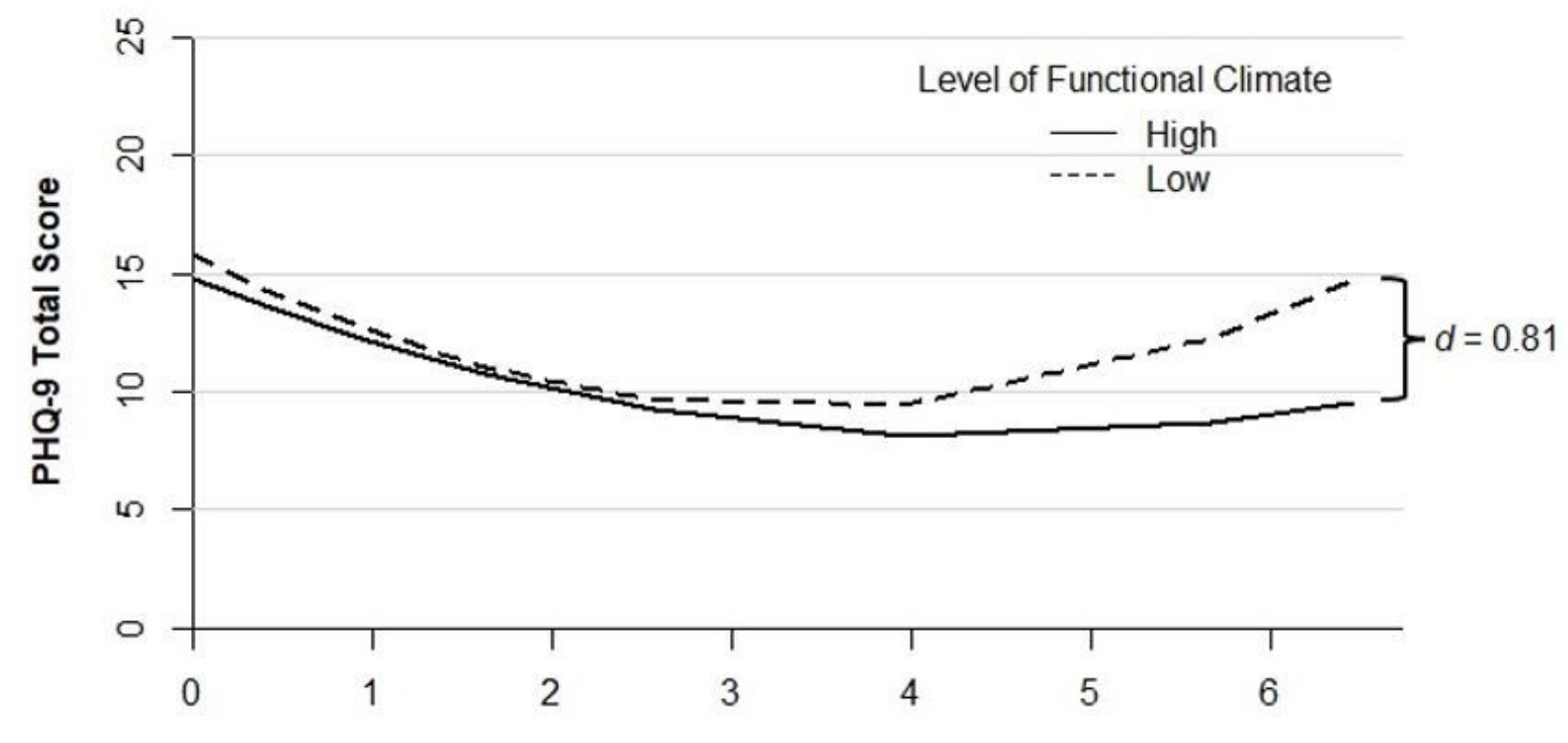

Months from Baseline

\section{Figure 1}

Relations between Proficient Organizational Culture and Functional Climate with Change in Patient Depression. Note: $\mathrm{N}=1,455$ observations, $\mathrm{N}=468$ patients, $\mathrm{K}=10 \mathrm{FQHCs}$. Low = average value of lower quartile. High = average value of upper quartile. Lines show the covariate-adjusted, average

\section{Supplementary Files}


This is a list of supplementary files associated with this preprint. Click to download.

- StaRIchecklistforauthorcompletionBennett.docx 